\title{
Surface treatment with UV-ozone to improve adhesion of vulcanized rubber formulated with an excess of processing oil
}

\author{
María Alejandra Moyano, José Miguel Martín-Martínez* \\ Adhesion and Adhesives Laboratory, University of Alicante, 03080 Alicante, Spain
}

\section{A R T I C L E I N F O}

\section{Article history:}

Accepted 9 July 2014

Available online 12 August 2014

\section{Keywords:}

Rubbers

Surface treatment

Peel

Boundary layer

\begin{abstract}
A B S T R A C T
An excess of processing oil was intentionally added in the formulation of vulcanized styrene-butadiene rubber for analyzing the effect on the treatment with UV radiation combined with ozone (UV-ozone) in improving the adhesion to waterborne polyurethane adhesive in footwear. Due to the excess of processing oil in the rubber, poor adhesion was expected. Both the length of the treatment and the distance between the UV radiation source to the rubber surface were studied, and the effects of the treatment on the surface chemistry, wettability and surface energy, and topography of the rubber were analyzed. The treatment of the rubber with UV-ozone removed hydrocarbon moieties and zinc stearate from the surface, and surface oxidation ( $\mathrm{C}-\mathrm{O}, \mathrm{C}=\mathrm{O}$ and $\mathrm{COO}^{-}$groups formation) occurred. As a consequence, improved wettability and increased surface energy (mainly due to the polar component of the surface energy) were obtained. The increase in the length of treatment and for a distance of 3-5 cm from the rubber to the UV radiation source favored the effectiveness of the UV-ozone treatment. Besides, whereas the UV-ozone treatment for 3 min produced the ablation of surface contaminants mainly, longer lengths of treatment (i.e., 6-9 $\mathrm{min}$ ) caused roughness and cracks on the rubber surface. The UVozone treatment also caused heating of the surface. Finally, the treatment with UV-ozone increased the adhesion of the rubber to waterborne polyurethane adhesive, the highest adhesion was obtained in the joints made with UV-ozone treated rubber for 3 and $6 \mathrm{~min}$ at a UV radiation source-rubber surface distance of $5 \mathrm{~cm}$.
\end{abstract}

(c) 2014 Elsevier Ltd. All rights reserved.

\section{Introduction}

Styrene-butadiene rubbers (SBRs) are commonly used as sole materials in footwear industry but their low surface energy [1] prevent good bonding to polyurethane adhesives, and surface treatments are mandatory to achieve good adhesion. In the existing literature, several surface treatments for rubbers have been proposed including abrasion and chemical treatments such as halogenation [2] or cyclization [3]. Solvent-based chlorination is the most widely used surface treatment for vulcanized rubber because an improvement in the mechanical adhesion (due to surface heterogeneities and cracks) and chemical adhesion (due to carbon-chlorine and carbon-oxygen functionalities) is produced. However, chlorination of rubber requires long times of reaction, organic solvents are needed, and chlorine is produced, being environmentally unacceptable and causing potential health problems. As a consequence, cleaner and faster radiation-based

\footnotetext{
* Corresponding author. Tel.: + 34 965903977; fax: +34 965909416.

E-mail address: jm.martin@ua.es (J.M. Martín-Martínez).
}

treatments have been proposed for rubber. Low-pressure plasma treatment improves the adhesion of rubbers due to the formation of polar moieties on the surface and ablation of low molecular weight compounds, but this treatment is difficult to carry out on line as vacuum is required [4]. On the other hand, UV radiation treatment combined with ozone has been shown effective in improving the adhesion of rubber to waterborne polyurethane adhesive [5].

Bolland [6] and Keller [7] proved the oxidant attack of the UV radiation in elastomers, and Blake and Bruce [8] studied the oxygen absorption speed on natural rubber after UV radiation exposure. When ozone is added during UV treatment, peroxy radicals are formed rending carbonyl and carboxyl functionalities that increased the wettability of the treated polymer $[9,10]$. The concentration of peroxy groups depended on the ozone concentration and the exposure time of the surface to ozone, among other factors [11]. The UV-ozone treatment affected only the outermost surface of the elastomers [12] and has been shown effective in improving the adhesion of several polymers $[13,14]$.

The effect of exposure to different ozone concentrations in conjunction with UV radiation on the surface modification and 
adhesion of block styrene-butadiene-styrene (SBS) rubber was studied [5]. Improved wettability, creation of oxygen-containing moieties at the surface, and ablation of the SBS rubber surface were obtained, more markedly by increasing the length of treatment. Whereas the treatment of SBS rubber with ozone only produced low peel strength values, adhesion was highly improved after UV or UV-ozone treatment. The modifications produced by UV and UV-ozone treatment were not restricted to the outermost SBS rubber surface but a thicker surface layer is modified, resulting in chain scission and the creation of low molecular weight oxidized material on the surface [5]. The additional ozone incorporated during UV radiation treatment enhanced the effects of UV-only treatment and improved the adhesion of SBS rubber. On the other hand, Romero Sánchez et al. [15] compared the effects produced by corona discharge and UV-ozone surface treatments in SBS rubber. They found that both treatments modified the rubber surface by creating $\mathrm{C}-\mathrm{O}, \mathrm{C}=\mathrm{O}$, and $\mathrm{COO}^{-}$moieties and improved wettability. The treatment with corona discharge did not create surface roughness but the treatment with UV radiation produced cracks on the rubber surface that favored the mechanical adhesion to solvent-borne polyurethane adhesive. Later study [16] showed that the UV-ozone treatment also produced the migration of the zinc stearate to the treated rubber surface decreasing adhesion.

Torregrosa Coque et al. [17] studied the incidence of different additives in the formulation of rubber on the effectiveness of the UV-ozone treatment, concluding that the migration of oils and lubricants competed negatively with the surface oxidation decreasing adhesion to solvent-borne polyurethane adhesive. The influence of adding $10 \mathrm{wt} \%$ calcium carbonate as filler in rubber surface treated with UV-ozone radiation has been studied [18], and although the improvement in wettability was similar in the rubber with and without filler, the presence of calcium carbonate inhibited the modifications produced for short length of treatment, decreasing the adhesion, while the surface oxidation of the filled rubber was favored for longer treatment times.

One drawback of the UV-ozone treatment of several polymers is the heating of the surface caused by the IR irradiation associated to the UV radiation treatment that caused deterioration of the adhesion [19]. To avoid it, two methods had been proposed: to perform a discontinuous UV radiation treatment and to add a thin film of water on the material just after treatment.

Considering the negative effect of low molecular weight additives in the effectiveness of the UV-ozone treatment of rubber, the aim of this study was to explore the potential of UV-ozone treatment in vulcanized rubber containing an excess of processing oil in its formulation. UV-ozone treatment of this rubber will be optimized for producing good adhesion to waterborne polyurethane adhesive, an aspect that will have great potential in avoiding the use of organic solvents and chemical in the bonding of upper to sole in footwear manufacturing.

\section{Experimental}

\subsection{Materials}

The vulcanized styrene-butadiene rubber used in this study (named as RC) was manufactured and provided by Invulsa (Quel, La Rioja, Spain) and its typical formulation is given in Table 1. RC rubber contains silica as filler and zinc stearate, which can be formed during the vulcanization by reaction of zinc oxide and stearic acid, and it contains an excess of paraffinic oil that was intentionally added for analyzing the effect of this low molecular weight additive in the performance of the UV-ozone treatment.

For adhesive joints formation, waterborne polyurethane dispersion Dispercoll-U54 (Bayer Materials Science AG, Leverkusen,
Table 1

Typical formulation of RC rubber.

\begin{tabular}{ll}
\hline Component & Percentage (phr) $^{\mathrm{a}}$ \\
\hline SBR rubber 1502 & 70 \\
Natural rubber & 30 \\
Precipitated silica & 30 \\
Sulfur & 1.5 \\
Benzothiazole disulfide & 1.5 \\
Tetramethyl tiuram disulfide & 0.5 \\
Poly(ethylene glycol) $\left(\mathrm{M}_{\mathrm{w}}=6000\right)$ & 1.1 \\
Zinc oxide & 1.5 \\
Stearic acid & 1.5 \\
Phenolic antioxidant & 0.5 \\
Microcrystalline paraffin wax & 1.0 \\
Paraffinic oil & $\mathbf{7 . 0}$ \\
\hline
\end{tabular}

${ }^{\mathrm{a}} \mathrm{phr}=$ parts per one hundred parts of rubber.

Table 2

Some characteristics of the waterborne polyurethane dispersion.

\begin{tabular}{ll}
\hline Solids content $\left(1 \mathrm{~h}\right.$ at $\left.105^{\circ} \mathrm{C}\right)[20]$ & $50 \mathrm{wt} \%$ \\
Brookfield viscosity $\left(23^{\circ} \mathrm{C}\right.$, Spindle S62, $\left.100 \mathrm{rpm}\right)$ & $133 \mathrm{mPa} . \mathrm{s}$ \\
$\mathrm{pH}$ & $7.2 \pm 0.1$ \\
Surface tension $\left(23^{\circ} \mathrm{C}\right.$, Nouy Ring) & $54 \mathrm{mN} / \mathrm{m}$ \\
Density $\left(20^{\circ} \mathrm{C}\right)[20]$ & $1.1 \mathrm{~g} / \mathrm{cm}^{3}$ \\
Average particle size [20] & $200 \mathrm{~nm}$ \\
\hline
\end{tabular}

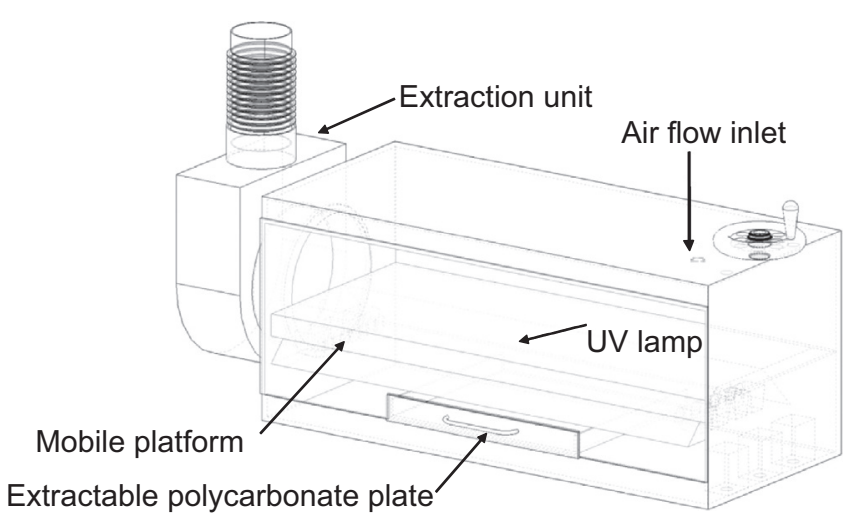

Fig. 1. Scheme of the UV-ozone treatment unit

Germany) was used. This is an aqueous dispersion of anionic polyurethane of high molecular weight. Its main characteristics are given in Table 2.

\subsection{UV radiation-ozone (UV-ozone) treatment}

UV-ozone treatment was carried out in equipment made in polycarbonate provided with low-pressure vapor grid mercury lamp (American Ultraviolet, Upland, CA, USA) (Fig. 1). Continuous UV radiation of the rubber was carried out. For avoiding heating of the rubber surface a continuous air renovation was used.

The UV lamp provides a radiation intensity of $10 \mathrm{~mW} / \mathrm{cm}^{2}$ measured at a distance of $5 \mathrm{~cm}$ from the lamp and produces UV radiation at the wavelengths of $254 \mathrm{~nm}$ (almost $90 \%$ of the total) and $185 \mathrm{~nm}$ (which is responsible of ozone formation by oxidizing air introduced continuously in the equipment). The equipment has an extraction unit to avoid high concentration of ozone and excessive heating of the lamp during treatment. The rubber sample is placed in an extractable polycarbonate plate which distance to the lamp can be varied. UV-ozone treatment was carried out by varying the distance between the UV lamp and the 
rubber surface $(1,3$ and $5 \mathrm{~cm})$ and the length of treatment $(3$, 6 and $9 \mathrm{~min})$.

\subsection{Experimental techniques}

\subsubsection{ATR-IR spectroscopy}

Bruker Alpha FTIR spectrometer (Bruker Optik GmbH, Ettlingen, Germany) was used to obtain the ATR-IR spectra of the asreceived and UV-ozone treated $\mathrm{RC}$ rubber. The incident angle of the IR radiation was $45^{\circ}$ and germanium prism was used. Hundred scans were obtained and averaged with a resolution of $4 \mathrm{~cm}^{-1}$. The study was carried out in $30 \times 10 \times 5 \mathrm{~mm}^{3}$ samples.

\subsubsection{X-ray photoelectron spectroscopy (XPS)}

The surface chemistry of the as-received and UV-ozone treated RC rubber was analyzed in VG Scientific Microtech Multilab spectrometer, using $\mathrm{Mg} \mathrm{K} \mathrm{K}_{\alpha} \mathrm{X}$-ray source $(1253.6 \mathrm{eV})$ with an incidence angle of $45^{\circ}$ and operating at $15 \mathrm{keV}$ and $300 \mathrm{~W}$. Prior to analysis, the rubber samples were outgassed in a vacuum chamber at a pressure lower than $5 \times 10^{-8}$ Torr. The analysis was performed on $8 \times 8 \times 1 \mathrm{~mm}^{3}$ samples. For each sample, a survey scan encompassing the region $0-1200 \mathrm{eV}$ was first obtained with a resolution of $4 \mathrm{eV}$. In a narrower energy interval $(20 \mathrm{eV})$ high resolution XPS spectra were obtained, and binding energies of all photopeaks were referenced to the $\mathrm{C} 1 \mathrm{~s}$ photopeak position for $\mathrm{C}-\mathrm{C}$ and $\mathrm{C}-\mathrm{H}$ (hydrocarbons) species at $285.0 \mathrm{eV}$.

\subsubsection{Contact angle measurements and calculation of the surface energy}

The wettability of the RC rubber before and after UV-ozone treatment was evaluated by contact angle measurements in RaméHart 100 goniometer (Ramé Hart, Netcong, NJ, USA). The test liquids used were deionized bi-distilled water (polar) and diiodomethane (nonpolar). The rubber pieces were placed into the hermetic and isothermal $\left(25^{\circ} \mathrm{C}\right)$ chamber of the goniometer previously saturated with the test liquid vapor. Drops of $4 \mu \mathrm{l}$ were placed on the rubber surface using a micro-syringe (Hamilton Instruments, Reno, NV, USA). Contact angle values were obtained 5 min after drop deposition. At least five drops placed in different locations on the surface were measured and averaged. The experimental error was \pm 2 degrees.

Surface energy and its polar and dispersive components were obtained by using the Owens-Wendt approach-Eq. (1):

$$
\begin{aligned}
& \left(1+\cos \theta_{w}\right)\left(\gamma_{w}^{d}+\gamma_{w}^{p}\right)=2\left(\sqrt{\gamma_{w}^{d} \gamma_{s}^{d}}+\sqrt{\gamma_{w}^{p} \gamma_{s}^{p}}\right) \\
& \left(1+\cos \theta_{i}\right)\left(\gamma_{i}^{d}+\gamma_{i}^{p}\right)=2\left(\sqrt{\gamma_{i}^{d} \gamma_{s}^{d}}+\sqrt{\gamma_{i}^{p} \gamma_{s}^{p}}\right)
\end{aligned}
$$

where $\theta_{\mathrm{w}}$ and $\theta_{\mathrm{i}}$ are the contact angle values measured with water and diiodomethane, respectively; $\gamma_{w}^{\mathrm{d}}$ and $\gamma_{\mathrm{i}}^{\mathrm{d}}$ are the dispersive components of the surface tension of water and diiodomethane, respectively; $\gamma_{\mathrm{w}}^{\mathrm{p}}$ and $\gamma_{1}^{\mathrm{P}}$ are the polar components of the surface tension of water and diiodomethane, respectively; and $\gamma_{s}^{\mathrm{p}}$ and $\gamma_{\mathrm{s}}^{\mathrm{d}}$ are the polar and dispersive components of the rubber, respectively.

\subsubsection{Scanning electron microscopy (SEM)}

The topography of the rubber surface before and after UVozone treatment was analyzed in JEOL JSM-840 (Peabody, MA, USA) scanning electron microscope. Samples of dimensions $10 \times 10 \times 5 \mathrm{~mm}^{3}$ were gold-coated before analysis and an electron beam of $20 \mathrm{kV}$ was used.

\subsubsection{T-peel test}

The adhesion properties were evaluated by T-peel tests of treated rubber-adhesive-treated rubber joints. The rubber specimens $\left(150 \times 30 \times 5 \mathrm{~mm}^{3}\right)$ were previously wiped with methyl ethyl ketone allowing evaporation of the solvent for $30 \mathrm{~min}$. Then, the samples were treated with UV-ozone, and immediately after treatment, the waterborne polyurethane adhesive was applied by brush, using $150 \mu \mathrm{m}$ metering rod to control the thickness. The solvent was allowed to evaporate for $1 \mathrm{~h}$ and then, the dried solid adhesive films were melted quickly at $90{ }^{\circ} \mathrm{C}$ under IR irradiation (reactivation process), joined and placed into hydraulic press under a pressure of $0.8 \mathrm{MPa}$ for $10 \mathrm{~s}$. T-peel test was carried out $72 \mathrm{~h}$ after joint formation in Instron 4411 (Instron Ldt., Buckinghamshire, UK) universal testing machine; a peeling rate of $0.1 \mathrm{~m} / \mathrm{min}$ was used. Five replicates were tested and averaged. The loci of failure of the joints were assessed by visual inspection.

\section{Results and discussion}

\subsection{Length of UV-ozone treatment}

Fig. 2a shows the ATR-IR spectra of the as-received, MEK-wiped and UV-ozone treated RC rubber during 3, 6, and 9 min at an UV lamp-rubber distance of $1 \mathrm{~cm}$. The ATR-IR spectrum of the asreceived $\mathrm{RC}$ rubber shows intense bands of the $\mathrm{CH}_{2}$ groups at 2909, 2841, 1468, 1459, 727, and $718 \mathrm{~cm}^{-1}$ corresponding to paraffin wax, processing oil, and rubber; furthermore, the band at $1535 \mathrm{~cm}^{-1}$ of zinc stearate appears and the intensity of the band at $1101 \mathrm{~cm}^{-1}$ of silica (filler in RC rubber) is quite low [21]. Therefore, the surface of the as-received RC rubber is covered by a layer of hydrocarbon-rich contaminants. MEK wiping reduces the intensity of the bands of the $\mathrm{CH}_{2}$ groups in the ATR-IR spectrum (Figs. 2.a and b), and an increase in the intensity of the bands of the rubber (i.e., styrene, $698 \mathrm{~cm}^{-1}$ ), butadiene $\left(963 \mathrm{~cm}^{-1}\right)$, and silica $\left(1101 \mathrm{~cm}^{-1}\right)$ is produced, indicating partial removal of contaminants in the RC rubber surface.

UV-ozone surface treatment was carried in MEK-wiped RC rubber. The ATR-IR spectra of Fig. 2a show a decrease of the intensity of the $\mathrm{CH}_{2}$ bands of the paraffinic wax (2909, 2842, 1450, 1394, 720 and $698 \mathrm{~cm}^{-1}$ ), the removal of zinc stearate $\left(1535 \mathrm{~cm}^{-1}\right)$, and the formation of a new band at $1708 \mathrm{~cm}^{-1}$ due to $\mathrm{C}=\mathrm{O}$ groups produced by oxidation of the $\mathrm{RC}$ rubber caused by the metastable species generated by UV radiation and ozone. Fig. 2b shows more clearly the noticeable decrease in the intensity of the $\mathrm{CH}_{2}$ bands ( 2909 and $2842 \mathrm{~cm}^{-1}$ ) in the RC rubber surface after UV-ozone treatment; however, the extent of removal of the $\mathrm{CH}_{2}$ moieties is not affected significantly by increasing the length of treatment. On the other hand, Fig. 2c shows the creation of several $\mathrm{C}=\mathrm{O}$ bands in the UV-ozone treated rubber between 1780 and $1660 \mathrm{~cm}^{-1}$ which intensity increases by increasing the length of treatment.

ATR-IR spectroscopy analyzes a surface depth of the rubber of about $1 \mu \mathrm{m}$ when Germanium prism is used. Therefore, the most external surface of the RC rubber was analyzed by XPS. The chemical composition of the MEK-wiped and UV-ozone treated rubber is given in Table 3. UV-ozone treatment decreases the carbon content and increases the oxygen and silicon content on the RC rubber surface due to surface oxidation and removal of hydrocarbon moieties (i.e., this causes an increase in silicon content of the silica filler on the rubber surface). The increase in the length of UV-ozone treatment increases the extent of the surface modifications on the RC rubber up to $6 \mathrm{~min}$.

The nature of the carbon-oxygen species created on the RC rubber surface by UV-ozone treatment was assessed from the curve fitting of the C1s photopeak (Table 4). The chemical composition on the MEK-wiped RC rubber surface consists of $\mathrm{C}-\mathrm{H}$ and $\mathrm{C}-\mathrm{C}$ species (92 at\%) that appear at a binding energy of 
a

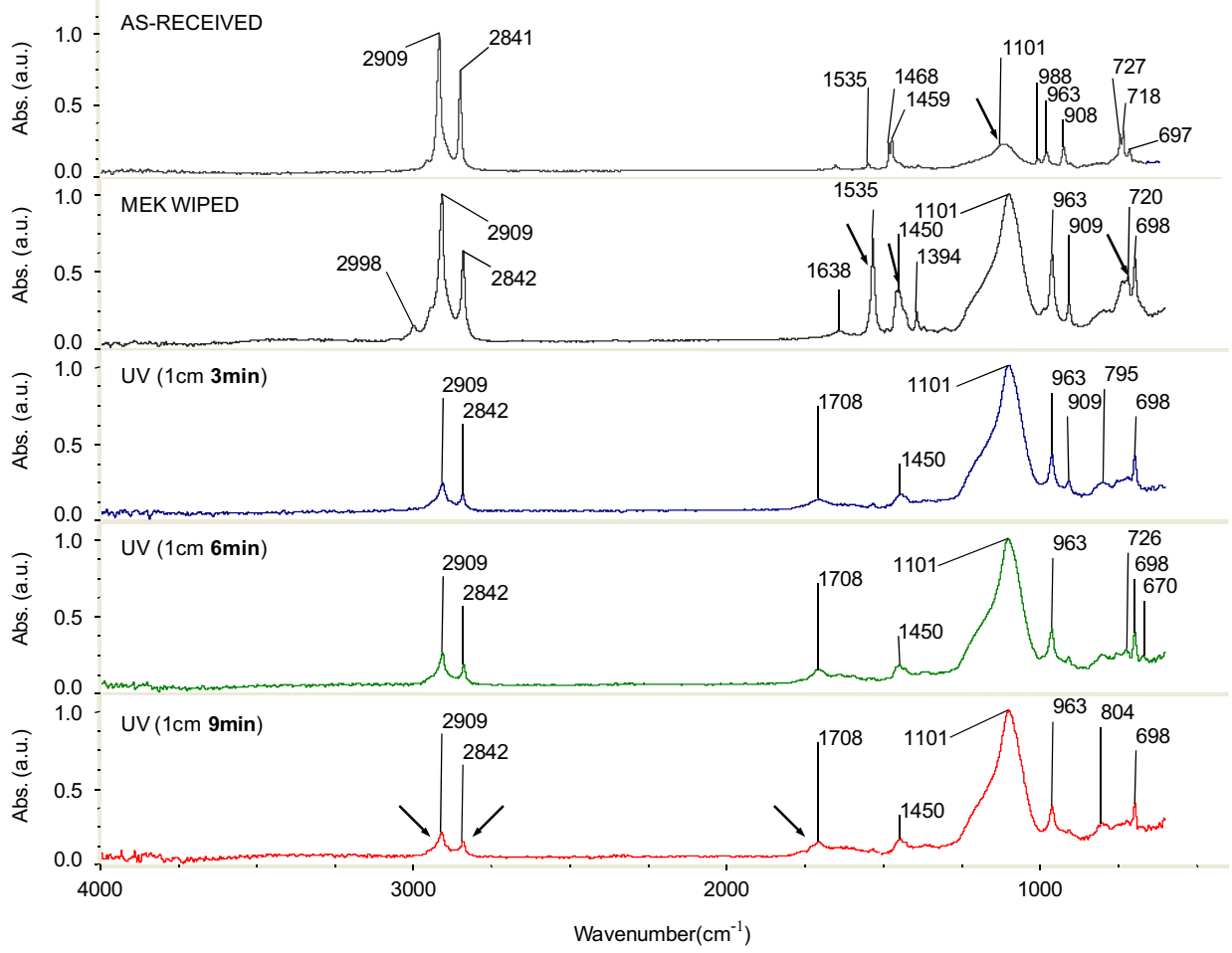

b

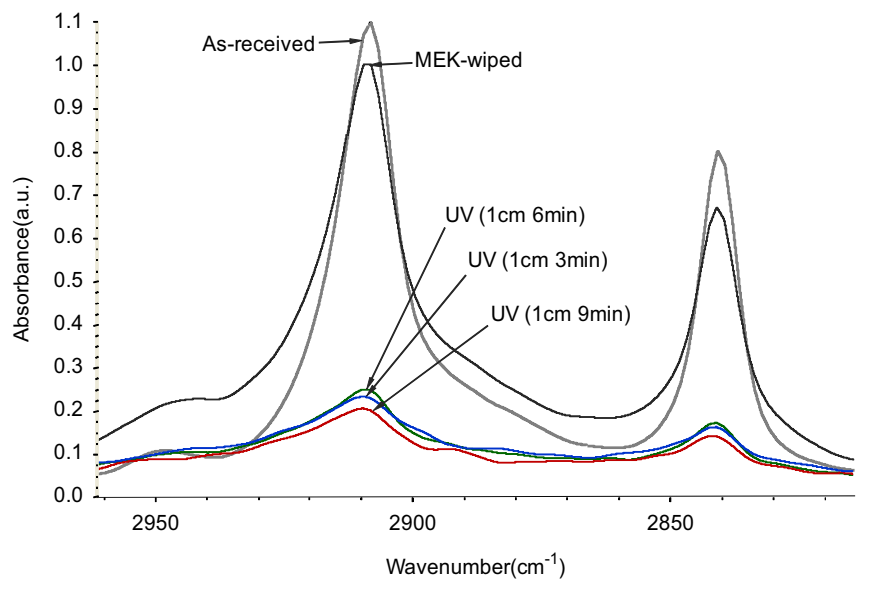

C

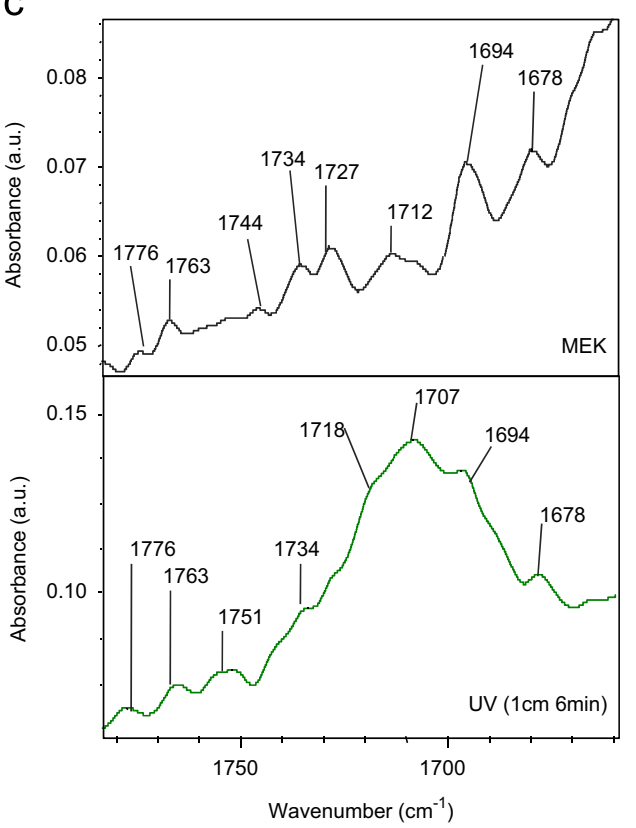

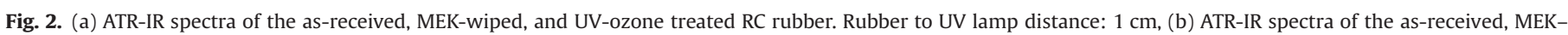

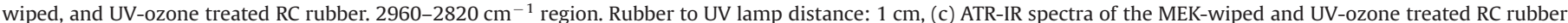
(1 min-6 cm). $1780-1660 \mathrm{~cm}^{-1}$ region.

$285.0 \mathrm{eV}$ and a small amount (8 at\%) of C-O moieties likely due to hydroxyl groups in the rubber formulation. The UV-ozone treatment for 3 min removes these hydroxyl groups and creates new $\mathrm{C}=\mathrm{O}$ groups (binding energy: $287.5 \mathrm{eV}$ ) caused by oxidation; the most noticeable change in surface chemistry is produced on the RC rubber surface treated with UV-ozone during 6 min as new $\mathrm{C}-\mathrm{O}$, $\mathrm{C}=\mathrm{O}$, and COO- moieties are created. The UV-ozone treatment during 9 min is also effective in creating new polar groups on the rubber surface.
The creation of the oxidized carbon-oxygen species on the RC rubber surface is responsible of the significant decrease on the contact angle values measured with water and diiodomethane (Table 5), although the contact angle values do not vary significantly by increasing the length of treatment. Therefore, the treatment with UV-ozone increases the surface energy of the RC rubber due mainly to an increase in the polar component of the surface energy $\left(\gamma_{\mathrm{s}}^{\mathrm{p}}\right)$; however, the dispersive component of the surface energy $\left(\gamma_{\mathrm{s}}^{\mathrm{d}}\right)$ is similar for the MEK-wiped and UV-ozone 
Table 3

Composition of MEK-wiped and UV-ozone treated RC rubber surface. UV lamprubber surface distance: $1 \mathrm{~cm}$. XPS experiments.

\begin{tabular}{lllll}
\hline \multirow{2}{*}{ Element } & \multicolumn{3}{l}{ Composition (at\%) } \\
\cline { 2 - 5 } & MEK wiped & UV-3 min & UV-6 min & UV-9 min \\
\hline C & 91 & 84 & 81 & 80 \\
O & 6 & 13 & 15 & 15 \\
Si & 3 & 3 & 4 & 5 \\
\hline
\end{tabular}

Table 4

Percentages of chemical species obtained from C1s photopeak of MEK wiped and UV-ozone treated RC rubber surface. UV lamp-rubber surface distance: $1 \mathrm{~cm}$. XPS experiments.

\begin{tabular}{lcccc}
\hline \multirow{2}{*}{ Species } & \multicolumn{4}{l}{ Percentage of species (at\%) } \\
\cline { 2 - 5 } & MEK wiped & UV-3 min & UV-6 min & UV-9 min \\
\hline C-H, C-C $(\text { B.e. }=285.0 \mathrm{eV})^{*}$ & 92 & 94 & 82 & 79 \\
C-O $($ B.e. $=286.2 \mathrm{eV})$ & 8 & 1 & 11 & 14 \\
$\mathrm{C}=\mathrm{O}($ B.e. $=287.6 \mathrm{eV})$ & 0 & 5 & 6 & 6 \\
COO $^{-}($B.e. $=289.4 \mathrm{eV})$ & 0 & 0 & 1 & 1 \\
\hline
\end{tabular}

* B.e.: Binding energy

Table 5

Contact angle values (water and diiodomethane, $25{ }^{\circ} \mathrm{C}$ ), polar $\left(\gamma_{\mathrm{s}}^{\mathrm{p}}\right)$ and dispersive $\left(\gamma_{s}^{\mathrm{d}}\right)$ components of the surface energy $\left(\gamma_{\mathrm{s}}\right)$ on the MEK wiped and UV-ozone treated RC rubber surface.

\begin{tabular}{|c|c|c|c|c|c|}
\hline \multirow[t]{2}{*}{ Surface treatment } & \multicolumn{2}{|c|}{ Contact angle (degrees) } & \multicolumn{3}{|c|}{ Surface energy $\left(\mathrm{mJ} / \mathrm{m}^{2}\right)$} \\
\hline & $\mathrm{H}_{2} \mathrm{O}$ & $\mathrm{CH}_{2} \mathrm{I}_{2}$ & $\gamma_{\mathrm{s}}^{\mathrm{p}}$ & $\gamma_{\mathrm{s}}^{\mathrm{d}}$ & $\gamma_{\mathrm{s}}$ \\
\hline MEK wiped & 86 & 58 & 4 & 26 & 30 \\
\hline UV-3 min & 46 & 41 & 27 & 27 & 54 \\
\hline UV-6 min & 49 & 39 & 24 & 29 & 53 \\
\hline UV-9 min & 42 & 36 & 28 & 29 & 57 \\
\hline
\end{tabular}

treated RC rubber, irrespective of the length of treatment. On the other hand, the surface tension of the polyurethane dispersion used for joint formation is $51 \mathrm{~mJ} / \mathrm{m}^{2}$. As the surface energy of the UV-ozone treated rubber is higher than the surface tension of the polyurethane dispersion, good wetting can be anticipated.

MEK wiping of RC rubber does not remove all contaminants from the surface (Fig. 3). However, the treatment with UV-ozone produces ablation removing surface contaminants (for short length of treatment), and roughness and cracks are created (for long length of treatment). UV-ozone treatment during 9 min seems too aggressive as deep cracks are produced.

Considering the increase in wettability and surface energy, the creation of carbon-oxygen moieties, and ablation and roughness on the RC rubber treated with UV-ozone, an increase in adhesion can be expected. In fact, whereas the T-peel strength of MEKwiped RC rubber-waterborne polyurethane adhesive-MEK wiped $\mathrm{RC}$ rubber joint is quite low $(<1 \mathrm{kN} / \mathrm{m})$ due to the presence of surface contaminants on the rubber surface, an increase is seen after treatment with UV-ozone, and a cohesive failure in the adhesive is always produced (Fig. 4).

The peel strength values decrease slightly by increasing the duration of treatment to up to $6 \mathrm{~min}$ and further increase by increasing the treatment to 9 min (Fig. 4). The initial decrease in peel strength value is not in agreement with the surface modifications produced on the RC rubber by treatment with UV-ozone, and therefore additional factors could affect the adhesion of UV-ozone treated RC rubber. Previous study [17] has shown that heating of vulcanized styrene-butadiene rubber between $40{ }^{\circ} \mathrm{C}$ and $60{ }^{\circ} \mathrm{C}$ favored the migration of low molecular weight substances from the bulk to the surface. In fact, due to the IR radiation produced by UV radiation during treatment some heating of the rubber surface can be produced [19]. Therefore, the temperature on the surface of the RC surface just after treatment with UV-ozone treatment was measured with Fluke IR thermometer FoodPro model (Digitron TM, Paterna, Spain). The temperatures measured on the treated RC rubber surface at a distance from the UV lamp of $1 \mathrm{~cm}$ were $31^{\circ} \mathrm{C}$ ( $3 \mathrm{~min}), 44{ }^{\circ} \mathrm{C}(6 \mathrm{~min})$ y $50{ }^{\circ} \mathrm{C}(9 \mathrm{~min})$. Therefore, UV-ozone treatment for more than 6 min could be more effective because of the surface modifications produced and the additional heating above $40{ }^{\circ} \mathrm{C}$ which will favor the migration of hydrocarbon moieties from the bulk to the RC rubber surface. The migration of these substances before adhesive joint formation would be positive for adhesion as once they are exposed to the surface they will dissolve into the polyurethane, avoiding their presence at the interface.

\subsection{UV lamp-rubber surface distance}

The influence of the distance between the UV-lamp and the rubber surface on the effect of the UV-ozone treatment of the RC rubber was also studied. Fig. 5 shows a noticeable reduction in the relative intensity of the hydrocarbon moieties (2909 and $2842 \mathrm{~cm}^{-1}$ ) in the RC rubber surface treated with UV-ozone for 6 min at different UV lamp-rubber distances, the most efficient removal was produced for distances of 1 and $5 \mathrm{~cm}$. The high reduction of hydrocarbon moieties (i.e., paraffin wax, processing oil) evidenced in the RC rubber treated at UV lamp-surface distance of $1 \mathrm{~cm}$ can be ascribed likely to the high temperature reached $\left(55^{\circ} \mathrm{C}\right)$.

The chemical changes in the most external surface on the RC rubber treated with UV-ozone were assessed by XPS. Table 6a shows that the UV-ozone treatment reduces the carbon content and increases the oxygen content on the RC rubber due to oxidation. For length of treatment of $3 \mathrm{~min}$, the UV lamp-surface distance does not influence the chemical surface modifications on rubber; however, for longer length of treatment, the highest degree of oxidation is produced for UV lamp-surface distance of $3 \mathrm{~cm}$. Similarly, for a given length of treatment, the higher level of oxidized carbon-oxygen species corresponds to a UV lamp-surface distance of $3 \mathrm{~cm}$. For length of treatment with UV-ozone of 6 or $9 \mathrm{~min}$ and UV lamp distances of 3 or $5 \mathrm{~cm}$, the dominant species on the $\mathrm{RC}$ rubber surface are $\mathrm{C}=\mathrm{O}$ groups; however, for a distance of $1 \mathrm{~cm}, \mathrm{C}-\mathrm{O}$ species are the most important (Table $6 \mathrm{~b}$ ). The less effectiveness of the RC rubber treated with UV-ozone at UV lampsurface distance of $1 \mathrm{~cm}$ can be ascribed to the air flow inlet design in the treatment unit. The radical species flow capable of oxidizing the rubber surface $\left(\mathrm{CO}_{2}, \mathrm{O}_{2}, \mathrm{O}_{3}\right)$ cannot be likely homogeneously renovated with new air inlet at such short distance. The relatively high time of residence of the oxidizing species created at $1 \mathrm{~cm}$ of distance will favor their recombination reducing the efficiency of the treatment.

The creation of carbon-oxygen polar groups on the RC rubber surface due to the UV-ozone treatment produces a decrease in the contact angle values measured with water (Fig. 6a) more noticeably by increasing the length of treatment and by increasing the UV lamp-rubber surface distance. However, an increase in water contact angle is produced for treatment during $3 \mathrm{~min}$, likely due to higher concentration of hydrocarbon moieties from the bulk to the surface (in agreement with the ATR-IR spectrum of Fig. 5). On the other hand, in general, an increase in the surface energy of the UVozone treated RC rubber is produced by increasing the length of 

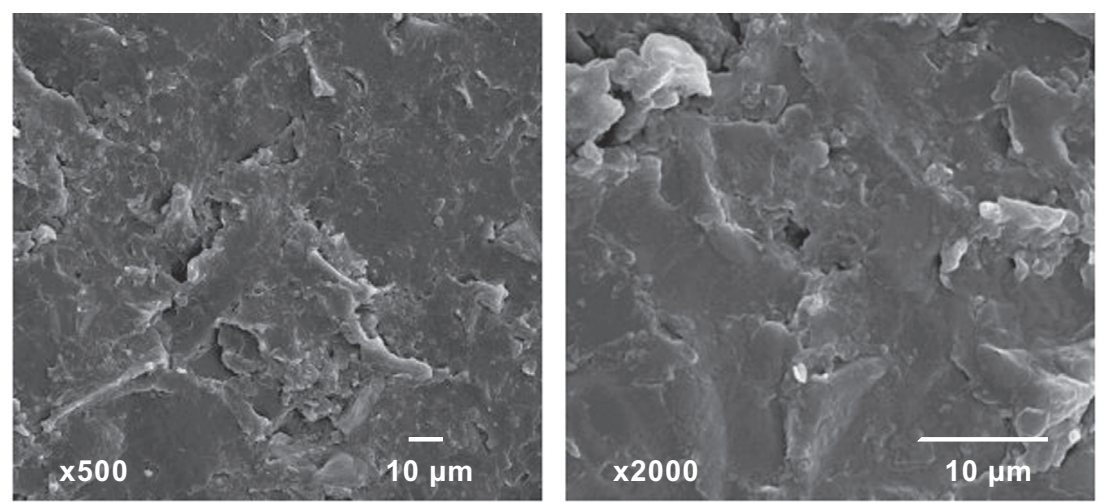

MEK-wiped
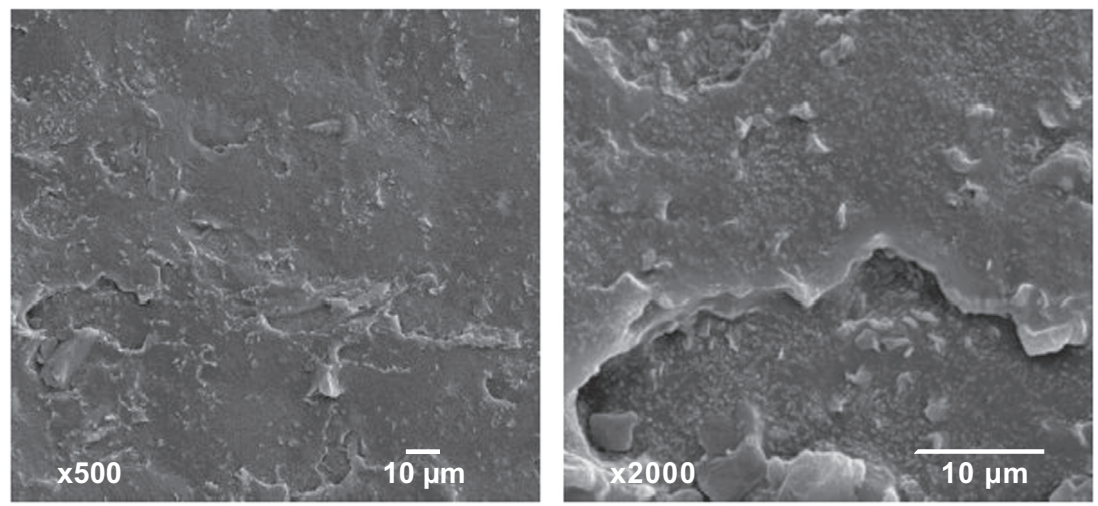

UV $1 \mathrm{~cm} 3 \mathrm{~min}$
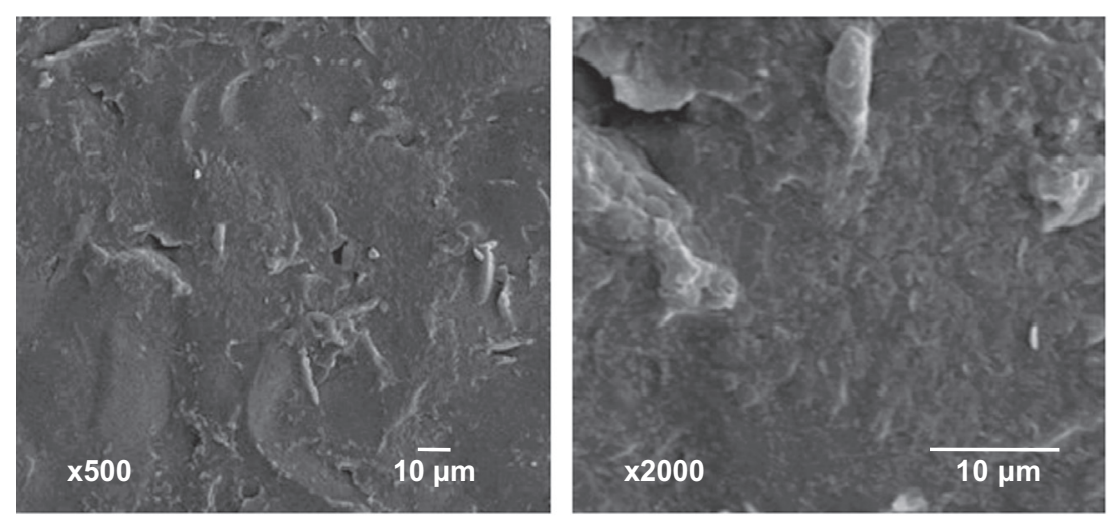

\section{UV $1 \mathrm{~cm} 6 \mathrm{~min}$}
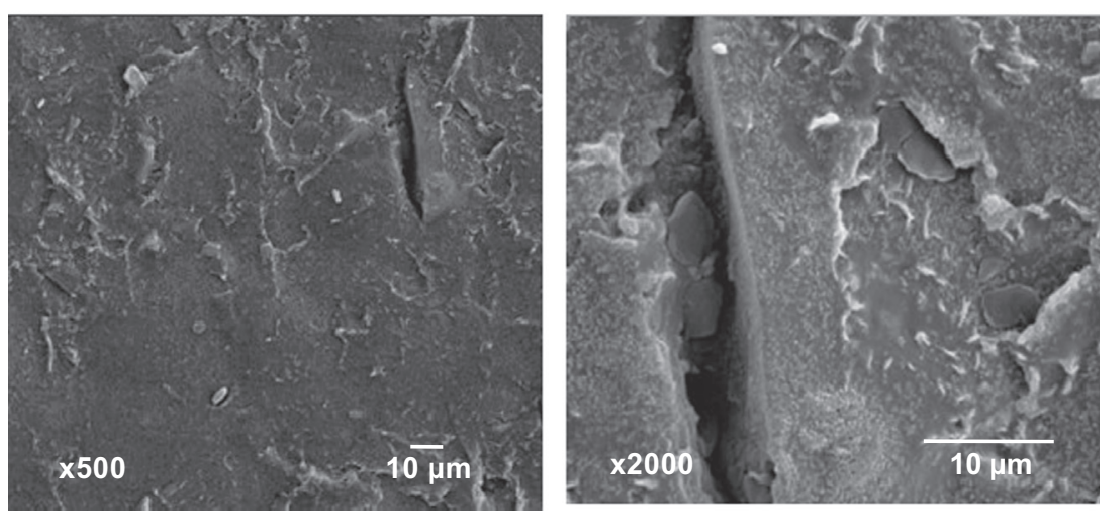

UV $1 \mathrm{~cm} 9 \mathrm{~min}$

Fig. 3. SEM micrographs of the MEK-wiped and UV-ozone treated RC rubber. 


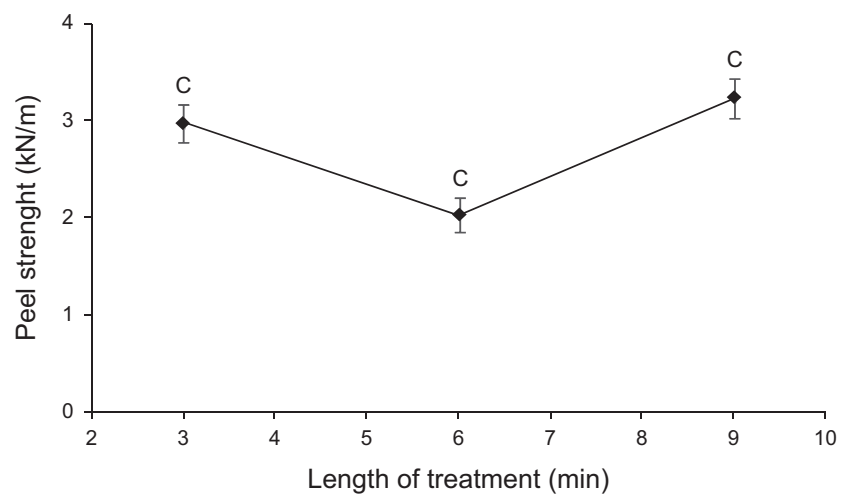

Fig. 4. T-Peel strength values of UV-ozone treated RC rubber/waterborne polyurethane adhesive/UV-ozone treated RC rubber as a function of the length of treatment. Values obtained 72 hrs after joints formation. Locus of failure: $\mathrm{C}=$ cohesive failure in the adhesive.

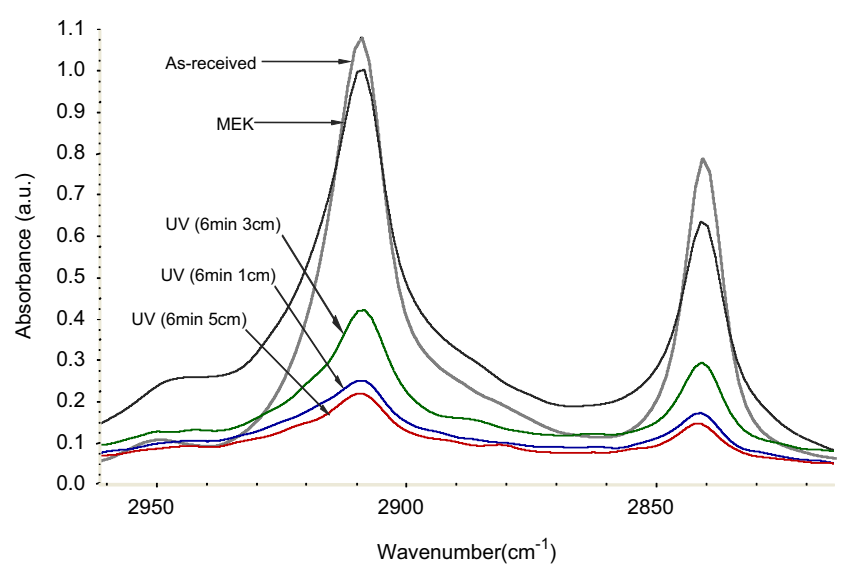

Fig. 5. ATR-IR spectra of the MEK wiped and UV-ozone treated RC rubber for 6 min at different UV lamp-sample distances. $2950-2820 \mathrm{~cm}^{-1}$ region.

Table 6a

Percentages of chemical species obtained from the C1s photopeak of the MEK wiped and UV-ozone treated RC rubber. XPS experiments.

\begin{tabular}{lllll}
\hline Surface treatment & $\begin{array}{l}\text { Length of } \\
\text { treatment (min) }\end{array}$ & \multicolumn{2}{l}{ Composition (at\%) } & \\
\cline { 3 - 5 } & & $C$ & 0 & $\mathrm{Si}$ \\
\hline MEK wiping & - & 91 & 6 & 3 \\
UV $1 \mathrm{~cm}$ & 3 & 84 & 13 & 3 \\
UV $3 \mathrm{~cm}$ & 3 & 85 & 12 & 3 \\
UV $5 \mathrm{~cm}$ & 3 & 85 & 13 & 2 \\
UV $1 \mathrm{~cm}$ & 6 & 80 & 16 & 4 \\
UV $3 \mathrm{~cm}$ & 6 & 76 & 21 & 3 \\
UV $5 \mathrm{~cm}$ & 6 & 85 & 12 & 3 \\
UV $1 \mathrm{~cm}$ & 9 & 80 & 15 & 5 \\
UV $3 \mathrm{~cm}$ & 9 & 69 & 26 & 5 \\
UV $5 \mathrm{~cm}$ & 9 & 80 & 16 & 4 \\
\hline
\end{tabular}

treatment and the UV lamp-rubber distance (Fig. 7a); however, the treatment of the RC rubber with UV-ozone during $3 \mathrm{~min}$ is an exception. Furthermore, the increase in the surface energy of the UV-ozone treated RC rubber is due to the increase in the polar component of the surface energy (Fig. 7b).

Peel strength values range between 2 and $3.5 \mathrm{kN} / \mathrm{m}$ and, in general, an increase in peel strength by increasing the length of
Table 6b

Percentages of species obtained from the C1s photopeak of the MEK wiped and UV-ozone treated RC rubber. XPS experiments.

\begin{tabular}{llllll}
\hline Surface treatment & Length of treatment (min) & \multicolumn{3}{l}{ Percentage of species (at\%) } \\
\cline { 3 - 6 } & & C-H, C-C & C-O & C=O & COO- $^{-}$ \\
\cline { 3 - 6 } & & 92 & 8 & 0 & 0 \\
\hline MEK wiped & - & 94 & 1 & 14 & 6 \\
UV $1 \mathrm{~cm}$ & 3 & 80 & 14 & 5 & 1 \\
UV $3 \mathrm{~cm}$ & 3 & 87 & 6 & 6 & 1 \\
UV $5 \mathrm{~cm}$ & 3 & 82 & 11 & 6 & 1 \\
UV $1 \mathrm{~cm}$ & 6 & 76 & 6 & 14 & 4 \\
UV $3 \mathrm{~cm}$ & 6 & 93 & 3 & 4 & 0 \\
UV $5 \mathrm{~cm}$ & 6 & 79 & 14 & 6 & 1 \\
UV $1 \mathrm{~cm}$ & 9 & 73 & 9 & 15 & 3 \\
UV $3 \mathrm{~cm}$ & 9 & 83 & 9 & 7 & 1 \\
UV $5 \mathrm{~cm}$ & 9 & & & &
\end{tabular}

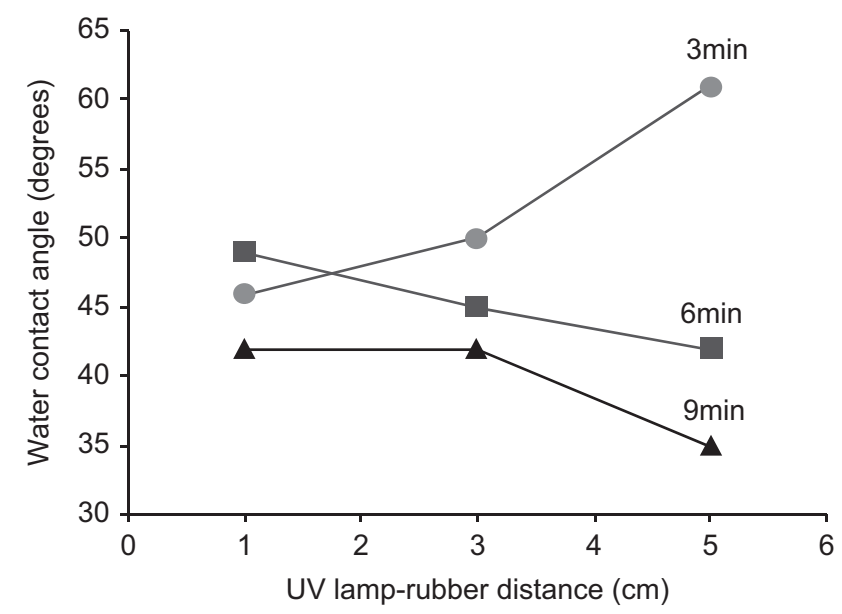

Fig. 6. Variation of the water contact angle values $\left(25^{\circ} \mathrm{C}\right)$ as a function of the UV lamp-rubber surface distance.

treatment and the UV lamp-rubber surface distance is obtained (Fig. 8). The combination of migration of hydrocarbon moieties, heating and surface oxidation of the rubber will be likely responsible for the different trend in the peel strength values of the joints made with the UV-ozone treated rubber during $3 \mathrm{~min}$. A cohesive failure in the adhesive was always obtained.

\section{Conclusions}

MEK wiping of rubber containing an excess of processing oil produced partial removal of hydrocarbon moieties on the surface that is insufficient for increasing adhesion to waterborne polyurethane adhesive.

UV-ozone treatment of MEK wiped rubber produced surface cleaning (removal of hydrocarbon moieties and zinc stearate), ablation, roughness and cracks formation, improved wettability, and increased surface energy due to oxidation $(C-O, C=O$, and $\mathrm{COO}^{-}$species were created). The effects of the UV-ozone treatment were more noticeable by increasing the length of treatment, particularly for $6 \mathrm{~min}$ or more, and for UV lamp-rubber surface distance of $3-5 \mathrm{~cm}$. On the other hand, the UV-ozone treatment produced heating of the rubber surface. Finally, the peel strength values of UV-ozone treated RC rubber-waterborne polyurethane adhesive-UV-ozone treated RC rubber joints were above $2 \mathrm{kN} / \mathrm{m}$ 
a

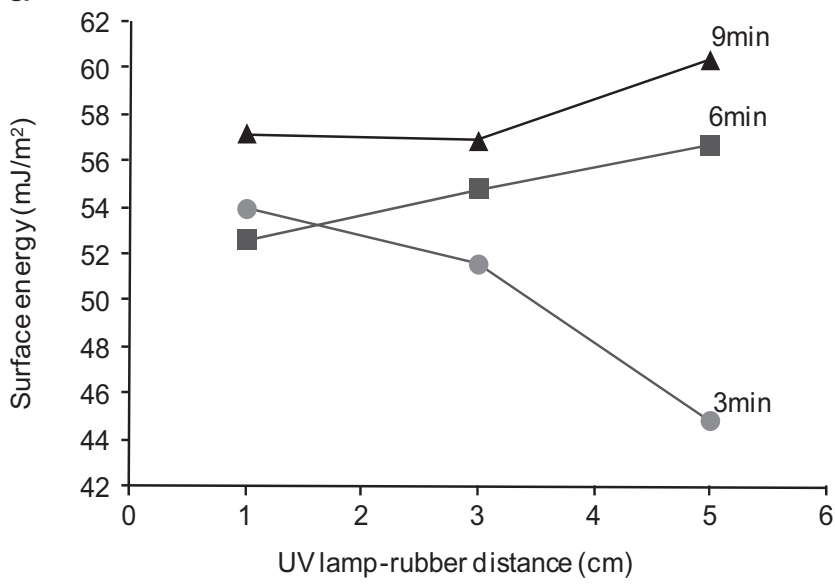

b

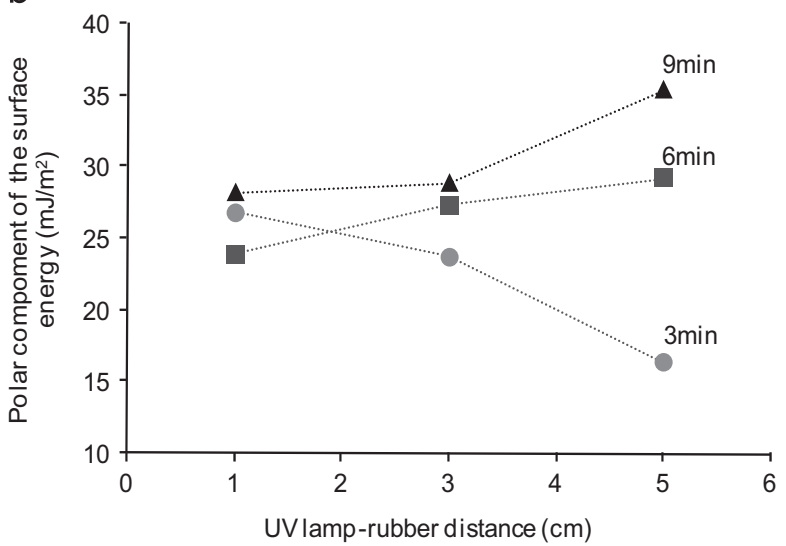

Fig. 7. (a) Variation of the surface energy of RC rubber treated with UV-ozone as a function of the UV lamp-rubber surface distance, (b) variation of the polar component of the surface energy of RC rubber treated with UV-ozone as a function of the UV lamp-rubber surface distance.

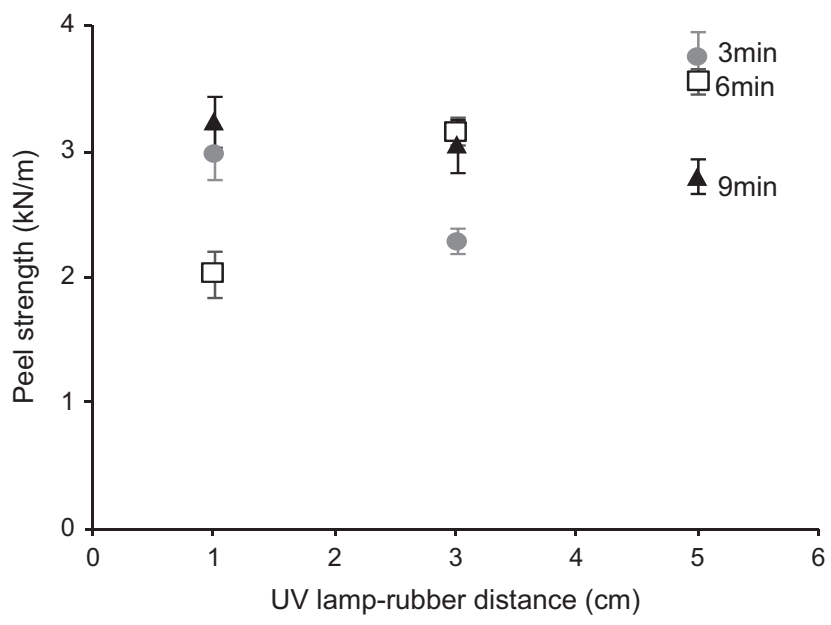

Fig. 8. Variation of the T-Peel strength values of the UV-ozone treated RC rubberwaterborne polyurethane adhesive-UV-ozone treated RC rubber joints. Values obtained 72 hrs after joint formation.

and showed cohesive failure in the adhesive, the highest values corresponded to treatment for 3 and $6 \mathrm{~min}$ at a distance from the UV lamp of $5 \mathrm{~cm}$.

\section{Acknowledgments}

Authors thank INVULSA (Quel, La Rioja, Spain) for supplying the rubber and Bayer (Leverkusen, Germany) for supplying the adhesive.

\section{References}

[1] Martín-Martínez JM. Improving adhesion of rubber. In: Bhowmick AK, editor. Current Topics in Elastomers Research. London (UK): CRC Press; 2007. p. 765-77 (Chapter 27)

[2] Bernabéu-Gonzálvez A, Pastor-Blas MM, Martín-Martínez JM. Adhesion improvement of SBR rubber by treatment with trichloroisocyanuric acid solutions in different esters. Int J Adhes Adhes 2001;21:325-37.

[3] Cepeda-Jiménez CM, Pastor-Blas MM, Ferrándiz-Gómez TP, Martín-Martínez JM. Surface characterization of vulcanized rubber treated with sulfuric acid and its adhesion to polyurethane adhesive. J Adhes 2000;73:135-60.

[4] Ortiz-Magán AB, Pastor-Blas MM, Ferrándiz-Gómez TP, Morant-Zacarés C, Martín-Martínez JM. Surface modifications produced by $\mathrm{N}_{2}$ and $\mathrm{O}_{2}$ RF-plasma treatment on a synthetic vulcanised rubber. Plasmas Polym 2001;6(12):81-105.

[5] Romero-Sánchez MD, Pastor-Blas MM, Martín-Martínez JM, Walzak MJ. Addition of ozone in the UV radiation treatment of a synthetic styrenebutadiene-styrene (SBS) rubber. Int J Adhes Adhes 2005;25(4):358-70.

[6] Bolland JL. Kinetics of olefin oxidation: Quarterly reviews. Chem Soc 1949;3 (1):1-93.

[7] Keller RW. Oxidation and ozonation of rubber. Rub Chem Tech 1985;58 (3):637-52.

[8] Blake JT, Bruce PL. Oxidation of unvulcanized rubber in light. Ind Eng Chem Res 1999;33:2489-501.

[9] Cheng F, Hong SG, Ho. CA. The adhesion properties of an ozone modified thermoplastic olefin elastomer. J Adh 1998;67(1-4):123-37.

[10] Rodriguez FHA, Santos EF, Feitosa JPA, Ricardo NMPS, De Paula RCM. Ozonation of unstretched natural rubber: Part I. Effect of film thickness. Rub Chem Tech 2001;74(1):57-68.

[11] Fujimoto K, Takebayashi Y, Inoue H, Ikada Y. Ozone-induced graft-polymerization onto polymer surface. J Polym Sci Polym Chem 1993;31(4):1035-43.

[12] Peeling J, Jazzar MS, Clark DT. An ESCA study of the surface ozonation of polystyrene film. J Polym Sci Polym Chem 1982(20):1797-805.

[13] Yamauchi J, Akiyoshi Y, Ikemoto K, Matsui T. Reaction mechanism for ozone oxidation of polyethylene as studied by ESR and IR spectroscopies. Bull Chem Soc Jap 1991;64:1173-7.

[14] Chtourou H, Riedl B, Kokta BV. Surface modification of polyethylene pulp fiber by ozone treatment. An analytical and thermal characterization. Polym Deg Stab 1994;43(1):149-56.

[15] Romero-Sánchez MD, Pastor-Blas MM, Martín-Martínez JM. Environmental friendly surface treatments of styrene-butadiene-styrene rubber: Alternatives to the solvent-based halogenation treatment. Int J Adhes Adhes 2005;25: 19-29.

[16] Romero-Sánchez MD, Pastor-Blas MM, Martín-Martínez JM, Zhdan PA, Watts JF. Surface modifications of a vulcanized rubber using corona discharge and ultraviolet radiation treatments. J Mat Sci 2001;36:5789-99.

[17] Torregrosa-Coque R, Alvarez-García S, Martín-Martínez JM. Migration of paraffin wax to sulphur vulcanized styrene-butadiene rubber (SBR) surface: Effect of temperature. J Adhes Sci Technol 2012;26:813-26.

[18] Romero-Sánchez MD, Walzak MJ, Torregrosa-Maciá R, Martín-Martínez JM. Surface modifications and adhesion of SBS rubber containing calcium carbonate filler by treatment with UV radiation. Int J Adhes Adhes 2007:27:434-45.

[19] A.S. Bhurke, P.A. Askeland, L.T. Drzal. Ultraviolet radiation surface treatment of polymers. In: G.L. Anderson, editor. 23rd annual meeting of the adhesion society, proceedings; February 2000, South Caroline (USA): Myrtle Beach.

[20] Dispercoll-U54 Technical data sheet. Coatings, Adhesives \& Specialties, Bayer Materials Science AG, Leverkusen, Germany (2011).

[21] A.B. Ortiz-Magán, M. Pastor-Blas, T.P. Ferrándiz-Gómez, J.M. Martín-Martínez. Treatment of vulcanized SBR rubber with low-pressure gas plasma using oxygen-nitrogen mixtures. In: K.L. Mittal, editors. Polymer Surface Modification: Relevance to Adhesion, Vol. 2, p. 96 (2000). 